\title{
Effect of Pyrodextrinization, Crosslinking and Heat- Moisture Treatment on In vitro Formation and Digestibility of Resistant Starch from African Locust Bean (Parkia biglobosa)
}

\author{
Abdoulaye Sankhon ${ }^{1,2}$, Wei-Rong Yao ${ }^{1^{*}}$, Issoufou Amadou ${ }^{1}$, Heya Wang ${ }^{1}$, He \\ Qian $^{1}$ and Moustapha Sangare ${ }^{2}$ \\ ${ }^{1}$ State Key Laboratory of Food Science and Technology, School of Food Science and Technology, Jiangnan University, Wuxi \\ 214122, PR China, ${ }^{2}$ Departement de Chimie Faculté des Sciences de la Nature Université Julius Nyereré de Kankan, Guinea \\ *For correspondence: E-mail: yaoweirongcn@jiangnan.edu.cn; Tel: +8651085328726; Fax: +8651085329081
}

\begin{abstract}
Purpose: This investigation was carried out to determine the impact of Parkia biglobosa starch modification on the fractions, namely rapidly digestible starch (RDS), slowly digestible starch (SDS), and resistant starch (RS).

Methods: Aqueous solution of sodium hypochlorite and potassium hydroxide was used to extract starch prior to modification by pyrodextrinization, cross-linking and heat-moisture treatment. Solubility, swelling power, x-ray diffraction, scanning electron microscopy (SEM) and thermal properties of the native and modified starches were also studied.

Results: Pyrodextrinization (PD), cross-linking (CL), and heat-moisture treatment (HMT) reduced the swelling power to $6.73,4.17$ and $5.57 \mathrm{~g} / \mathrm{g}$, respectively but increased solubility by $59.0,41,41.5$ and $39.5 \%$, respectively, and tended to decrease gelatinization enthalpy $(\Delta H)$. Starch yield was $25.7 \%$ on a whole seed basis. RS content significantly $(p<0.05)$ increased to $46.3,49.2$ and $45.3 \%$, respectively following $P D, C L$ and HMT. X-ray diffraction resulrs indicate the presence of $V$-type crystallinity in the modified parkia starch while SEM showed PD and CL starch structures were more compact and dense than HMT starch which was irregularly-shaped formed.

Conclusion: Native parkia starch modified by pyrodextrinization, cross-linking and heat-moisture treatment showed appreciably higher thermal stability which makes it suitable for incorporation in foods that are subject to high temperature processing and high shear.
\end{abstract}

Keywords: Pyrodextrinization, Crosslinking, Heat-moisture treatment, Gelatinization, Resistant starch, Parkia biglobosa

Tropical Journal of Pharmaceutical Research is indexed by Science Citation Index (SciSearch), Scopus, International Pharmaceutical Abstract, Chemical Abstracts, Embase, Index Copernicus, EBSCO, African Index Medicus, JournalSeek, Journal Citation Reports/Science Edition, Directory of Open Access Journals (DOAJ), African Journal Online, Bioline International, Open-J-Gate and Pharmacy Abstracts

\section{INTRODUCTION}

Native starch finds applications in various industries, the researches for new sources of starch, like Africa locust bean (Parkia biglobosa), becomes necessary. Qualitative determination of the chemical and nutritional composition of $P$. biglobosa seeds revealed that it is rich in starch, lipids, protein, carbohydrates, soluble sugars, and ascorbic acid [1]. Therefore, starch modification is commonly achieved through derivatisation (etherification, esterification, crosslinking and grafting), decomposition (acid or 
enzymatic hydrolysis and oxidation) and physical treatment (using heat or moisture) [2].

The resistant starch (RS) represents one of the most important functional ingredients that have recently emerged from food science and pharmaceuticals research [3]. It has generally been defined as the fraction of dietary starch that is not digested in the small intestine of healthy individuals [4]. RS has been divided into four categories, which are type-1, $-2,-3$, and -4 for physically inaccessible starch, raw crystalline starch, retrograded starch, and chemically modified starch, respectively [5]. It was previously reported that RS type-3 can be produced by physical treatments including heatmoisture [6]. On the other hand, RS type-4 is produced by chemical reactions, in particular, cross-linking where sodium trimetaphosphate/ sodium tripolyphosphate (STMP/STPP), or a mixture of acetic anhydride and adipic acid have been used as cross-linking agents [7].

Wang et al [8] showed that indigestible material content in dextrins obtained from starches modified by pyrodextrinization is inversely proportional to the amount of 1-4 glycosidic bonds, and that these dextrins exhibit characteristics similar to those of dietary fiber. Dextrins can be produced by dry pyroconversion, in which acid hydrolyzes the starch and preferentially attacks the amorphous regions, leaving a highly crystalline starch.

Digestibility of starch fractions obtained from $P$. biglobosa seeds has not been carried out. Therefore, the objective of this study was to evaluate the effect of pyrodextrinization, crosslinking and heat-moisture on in vitro digestibility and formation of resistant starch of an African locust bean. This could be of great interest to industries looking for slow digestible starch instead of resistant starch. In addition, swelling, and solubility properties, $\mathrm{x}$-ray diffraction, scanning electron microscopy and thermal properties of the native modified starches were also determined.

\section{EXPERIMENTAL}

\section{Materials}

African locust bean ( $P$. biglobosa) seeds were purchased and authenticated by Dr Moustapha Sangare (Departement Chimie Faculté des Sciences de la Nature, Université Julius Nyereré de Kankan, Guinea) in August, 2011, and shipped to Wuxi, China through $\mathrm{TNT}^{\circledR}$ mailing company (No. GD923580841WW). Porcine enzymes (invertase, pancreatic a-amylase, amyloglucosidase) were purchased from SigmaAldrich, Inc. (Shanghai, China). Potassium hydroxide, sodium hypochlorite, ethanol, 3, 5dinitro salicylic acid were purchased from Sinopharm Chemical Reagent Co., Ltd (Shanghai, China). All other reagents used were of analytical grade.

\section{Starch isolation}

Starch was isolated from $1 \mathrm{~kg} P$. biglobosa seeds according to the method of Perez-Sira \& Amaiz [9] with slight modification. The seeds were steeped in a solution of sodium hypochlorite (35 g) and potassium hydroxide $(50 \mathrm{~g})$ in water $(2 \mathrm{~L})$ at room temperature $\left(28{ }^{\circ} \mathrm{C}\right)$ for $3 \mathrm{~h}$. The $\mathrm{pH}$ of the solution was elevated to 9 , and the mixture was maintained at $100{ }^{\circ} \mathrm{C}$ in a thermostatted water bath for $3 \mathrm{~h}$. The solution was then drained and the seeds were immersed in water and left overnight at ambient temperature. Finally, the seeds were thoroughly washed, manually dehulled, and the cotyledon was washed repeatedly until the $\mathrm{pH}$ of the washings was neutral. The cotyledon was blended with water for $24 \mathrm{~h}$ using a domestic blender. The homogenate was filtered through muslin cloth and the filtrate was allowed to settle overnight. The supernatant was decanted, and the sediment was centrifuged at $4500 \mathrm{rpm}$ for $10 \mathrm{~min}$ using a ZOPR-52D refrigerated centrifuge (Hitachi Koki Co Ltd, Tokyo, Japan). The sedimented starch was re-suspended in water, and the process was repeated six times. The resultant starch was dried at $60{ }^{\circ} \mathrm{C}$ in a hot air oven, then ground into powder using a mortar and pestle and stored in cellophane. The yield of starch was determined.

\section{Proximate analysis}

Moisture, ash, total protein, and total fat content of the native parkia starch were carried out according to AACC [10] methods. The apparent amylose content was determined by dissolving $20 \mathrm{mg} \mathrm{db}$ starch in $10 \mathrm{ml}$ of a $0.5 \mathrm{~N} \mathrm{KOH}$ solution in a test tube. The mixture was vigorously mixed and then heated in a boiling water bath for 10 min. The test tubes were then cooled to ambient temperature $\left(28{ }^{\circ} \mathrm{C}\right)$ and the mixture diluted with water to $100 \mathrm{ml}$ in a volumetric flask. The diluted solution $(1.0 \mathrm{ml})$ was mixed with $1 \mathrm{ml}$ of $0.5 \mathrm{~N} \mathrm{HCl}$ and $0.5 \mathrm{ml}$ iodine solution (2\% potassium iodide $(\mathrm{KI})$ and then adjusted to a final volume of $50 \mathrm{ml}$. After the contents were allowed to stand for 15 $\min$ at ambient temperature $\left(28{ }^{\circ} \mathrm{C}\right)$, the absorbance was measured at $640 \mathrm{~nm}$. 


\section{Starch modification}

\section{Pyrodextrinization}

Briefly, $5 \mathrm{~g}$ of starch was placed in $20 \mathrm{ml}$ glass Petri dishes and 2.2 M hydrochloric acid was added. The starch/ $\mathrm{HCl}$ ratio was $80: 1$ (w/v). The acid was dispersed on the starch and the mixture was allowed to react for $16 \mathrm{~h}$ at room temperature. After that the mixture was dried in an oven at $110{ }^{\circ} \mathrm{C}$ for $3 \mathrm{~h}$ and grinded to pass through a $100 \mu \mathrm{m}$ sieve.

\section{Crosslinking}

A starch sample $(10 \mathrm{~g})$ was mixed with $20 \mathrm{ml}$ water containing $1.2 \mathrm{~g}$ sodium trimetaphosphate and $1.0 \mathrm{~g}$ sodium sulfate. The $\mathrm{pH}$ of the slurry was adjusted to 11.5 using $1.0 \mathrm{M}$ sodium hydroxide and the mixture was stirred at $45^{\circ} \mathrm{C}$ for $3 \mathrm{~h}$. After cooling the $\mathrm{pH}$ was adjusted to 6.5 using $1.0 \mathrm{M}$ hydrochloric acid. The product was washed with distilled water and centrifuged at $4000 \times \mathrm{g}$ for $10 \mathrm{~min}$ four times and freeze dried (Cryodos-50, Telstar, Terrassa, Spain). Dried starches were ground to pass through a $100 \mu \mathrm{m}$ sieve.

\section{Heat-moisture treatment (HMT)}

Starch powder was weighed into glass jars and the moisture level was increased to $20 \%$ by adding the appropriate amount of distilled water. The mixture was stirred and the glass jars sealed before equilibration at room temperature $\left(28^{\circ} \mathrm{C}\right)$ for $24 \mathrm{~h}$. Then, the jars were placed into air oven for $24 \mathrm{~h}$ at $110{ }^{\circ} \mathrm{C}$. After cooling at ambient temperature, the jars were opened and the samples were dried at $30^{\circ} \mathrm{C}$ for $48 \mathrm{~h}$ in air oven. Subsequently starch was ground to powder using a mortar and pestle pass through a $100 \mu \mathrm{m}$ sieve.

\section{In vitro digestibility}

Five hundred milligrams of starch fractions: total starch (TS), rapidly digestible starch (RDS), slowly digestible starch (SDS) and resistant starch (RS) were measured. Samples were incubated with invertase, pancreatic $\alpha$-amylase and amyloglucosidase at $37^{\circ} \mathrm{C}$ in capped tubes immersed in a water bath shaker and the supernatants were measured at $0 \mathrm{~min}, 20 \mathrm{~min}$, and $120 \mathrm{~min}$ for glucose content. The glucose data obtained were used to compute the content of various starch types as in Eqs 1-4.

$\mathrm{TS}=(\mathrm{TG}-\mathrm{FG}) \times 0.9$

$\mathrm{RDS}=(\mathrm{G} 20-\mathrm{FG}) \times 0.9$

$\mathrm{SDS}=(\mathrm{G} 120-\mathrm{G} 20) \times 0.9$

$\mathrm{RS}=\mathrm{TS}-(\mathrm{RDS}+\mathrm{SDS})$ where, free glucose (FG), G20 and G120 (mg) represent the amount of glucose in the supernatant at $0 \mathrm{~min}, 20 \mathrm{~min}$ and $120 \mathrm{~min}$ of hydrolysis, respectively. Total glucose (TG) was measured with 3,5-dinitrosalicylic acid after the starch was completely hydrolyzed into glucose by perchloric acid [11]. The in vitro digestibility of starch was determined from the calibration curve $\left(y=0.743 x+0.0004\right.$, and $\left.R^{2}=0.9958\right)$ equation.

\section{Swelling power and solubility}

Mixing of $0.6 \mathrm{~g}$ starch (native or modified) with 30 $\mathrm{ml}$ of distilled water and stirred at $85{ }^{\circ} \mathrm{C}$ on a magnetic stirrer for $30 \mathrm{~min}$ then the mixture was centrifuged (Hitachi Koki Co Ltd, Tokyo, Japan) at $2026 \times \mathrm{g}$ for $15 \mathrm{~min}$. The supernatant was carefully removed, and the swollen starch sediment was weighed $\left(M_{1}\right)$. The supernatant was evaporated and dried at $105^{\circ} \mathrm{C}$ in an oven until constant weight $\left(\mathrm{M}_{2}\right)$. Swelling power and solubility were calculated as in Eqs 5 and 6.

Swelling power $=\frac{M 1}{M 0}$

Solubility $\%=\frac{M 2}{M 0} \times 100$

where $M_{0}$ is the initial dry weight of the starch sample

\section{Scanning electron microscopy (SEM)}

SEM samples were gold-coated and scanned using an Electro Scan Quanta 200 environmental scanning microscope (Fei Company, Netherlands).

\section{X-ray powder starch diffraction}

X-ray powder diffraction apparatus (Shimadzu Lab XRD-6000) was used to examine the crystalline property of the starch samples. The scanning range was from $2^{\circ}$ to $40^{\circ}$ and it covered all the significant diffraction peaks of starch crystallites.

\section{Differential scanning calorimeter (DSC)}

Gelatinization temperature and enthalpy of the processed parkia starch product were analyzed with the Pyris-1 DSC (PE, USA). The sample (2 - $3 \mathrm{mg}$ ) was placed in sample aluminum pans together with deionizer water; after sealing, the pans were left to equilibrate at room temperature $\left(28^{\circ} \mathrm{C}\right)$ and then heated to $120^{\circ} \mathrm{C}$ at $10^{\circ} \mathrm{C} / \mathrm{min}$. An empty pan was used as reference.

\section{Statistical analysis}

The test results were processed by one-way analysis of variance (ANOVA) test using a 
statistical software (SAS, version 8.1). Differences at $p<0.05$ were considered to be significant.

\section{RESULTS}

The chemical compositions are as followed: yields (on total seed basis) $25.7 \%$ pure starch, and the isolated parkia starch showed low ash, protein and fat contents of $0.16,0.09$ and 0.12 $\%$, respectively. The amylose content of parkia starch was $32.6 \%$, which is similar to previously reported values of 30.1 - $34.4 \%$ [6] in lentil starches.

\section{Effect of method modification on parkia starch}

The proportion of the RDS, SDS, and RS of native and modified parkia starch are shown in Figure 1. Impact of PD, CL and HMT on parkia starch has the lowest RDS with 12.54, 11.35 and $11.45 \%$, respectively, which were expected since their granular structure was disrupted during modification and thus, became more susceptible to enzymatic hydrolysis.

SDS fraction was low in content after PD, CL and HMT modifications, yielding 41.1, 39.4 and 43.3 $\%$, respectively. After PD, CL and HMT treatment, RS content increased significantly to 46.3, 49.2 and $45.3 \%$, respectively. Similar results were reported by Campechano-Carrera et al [12] with the effect of PD on starch yielding $47.5 \%$ resistant starch content for Lima bean and $62.8 \%$ for cowpea. The effect of crosslinking on corn starch showed that RDS content decreased from 58.1 to $28.6 \%$, SDS content from 36.5 to $12.7 \%(p<0.05)$ while RS content increased from 5.5 to $58.7 \%$ with increasing concentration of cross-linking reagent [13].

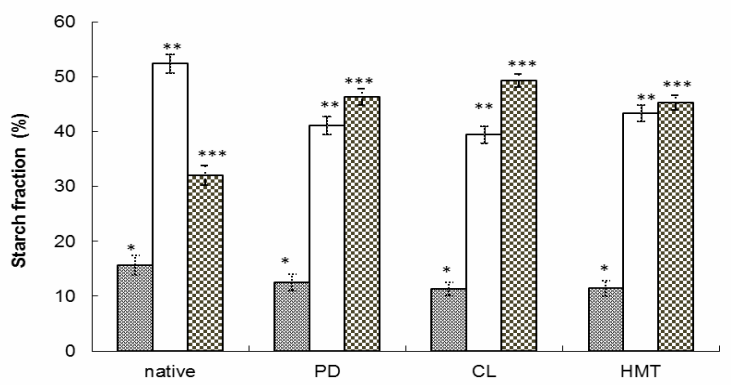

Figure 1: Effect of pyrodextrinization (PD), crosslinking $(\mathrm{CL})$ and heat-moisture (HMT) treatments on parkia starch. Data are mean and standard deviation with significant differences $(p<0.05)$ for $\%$ starch fractions: RSD $(*)$, SDS $(* *)$ and RS $(* *)$.

\section{Effect of treatments on swelling power and solubility of native parkia starch}

Swelling power and solubility of the starch samples, determined at $85^{\circ} \mathrm{C}$, are given in Table 1. The effect of PD, CL and HMT of parkia starch on swelling power was significantly low in native starch $(p<0.05)$. The solubility of HMT starches increased sharply when the temperature was increased above $70{ }^{\circ} \mathrm{C}$.

Table 1: Swelling power and solubility of native parkia starch following pyrodextrinization, cross-linking and heat-moisture treatment

\begin{tabular}{lcl}
\hline Parkia starch & $\begin{array}{l}\text { Swelling } \\
\text { power }(\mathbf{g} / \mathbf{g})\end{array}$ & $\begin{array}{l}\text { Solubility } \\
(\%)\end{array}$ \\
\hline Native starch & $8.74 \pm 0.80^{\mathrm{a}}$ & $26.1 \pm 1.2^{\mathrm{d}}$ \\
Pyrodextrinization & $6.73 \pm 0.50^{\mathrm{b}}$ & $59.0 \pm 2.3^{\mathrm{a}}$ \\
Cross-linking & $4.17 \pm 0.70^{\mathrm{d}}$ & $41.5 \pm 0.9^{\mathrm{b}}$ \\
Heat-moisture treatment & $5.57 \pm 0.40^{\mathrm{c}}$ & $39.5 \pm 0.7^{\mathrm{c}}$ \\
\hline Values are expressed as mean \pm standard deviation $(n=3)$. \\
Mean values in the same column with different superscript \\
letters $(a, b, c$ and $d)$ are significantly different $(p<0.05)$
\end{tabular}

\section{Scanning electron microscopy (SEM)}

The effect of PD, CL and HMT on the SEM images of modified parkia starch is compared with that of native parkia starch in Figure 2. It illustrates that the modification of native parkia starch by PD, CL and HMT altered the starch structure. While native starch exhibited a granular appearance (Figure 2a), the use of PD and $\mathrm{CL}$ agents appeared to make the starch structure more compact and dense (Figure 2b and c). On the other hand, the granular structure disappeared and a continuous network with irregular shape was formed in the physically modified starch (Figure 2d).
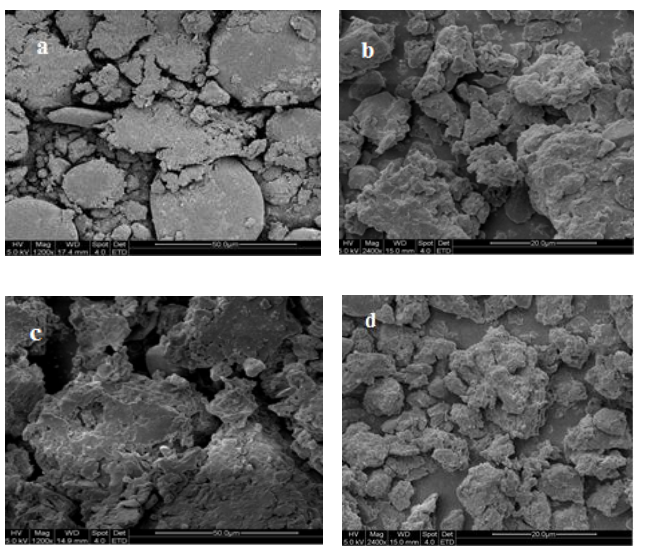

Figure 2: Scanning electron micrographs of native starch (a) and of those modified by pyrodextrinization (PD, b), cross-linking (CL, c) and heat-moisture (HMT, d) treatments 
Table 2: Thermal properties of native and pyrodextrinization (PD), cross-linking (CL) and heat-moisture (HMT)modified parkia starches

\begin{tabular}{lcccc}
\hline Parkia starch & $\mathbf{T}_{\mathrm{o}}\left({ }^{\circ} \mathbf{C}\right)$ & $\mathbf{T}_{\mathbf{p}}\left({ }^{\circ} \mathbf{C}\right)$ & $\left.\mathbf{T}_{\mathbf{c}} \mathbf{(}^{\mathrm{C}} \mathbf{C}\right)$ & $\Delta \mathbf{H}(\mathbf{J} / \mathbf{g})$ \\
\hline Native starch & $62.7 \pm 0.8^{\mathrm{c}}$ & $89.6 \pm 0.3^{\mathrm{a}}$ & $62.7 \pm 0.5^{\mathrm{d}}$ & $13.93 \pm 0.20^{\mathrm{a}}$ \\
Pyrodextrinization (PD) & $60.3 \pm 0.4^{\mathrm{d}}$ & $72.4 \pm 0.2^{\mathrm{d}}$ & $95.7 \pm 0.3^{\mathrm{b}}$ & $6.81 \pm 0.40^{\mathrm{c}}$ \\
Cross-linking (CL) & $69.6 \pm 0.9^{\mathrm{a}}$ & $81.8 \pm 0.6^{\mathrm{c}}$ & $93.6 \pm 0.3^{\mathrm{c}}$ & $5.29 \pm 0.30^{\mathrm{d}}$ \\
Heat-moisture (HMT) & $63.7 \pm 0.6^{\mathrm{b}}$ & $82.5 \pm 0.4^{\mathrm{b}}$ & $103.6 \pm 0.4^{\mathrm{a}}$ & $8.94 \pm 0.60^{\mathrm{b}}$ \\
\hline
\end{tabular}

Values are expressed as mean \pm standard deviation $(n=6)$; mean values in the same column with different letters are significantly different $(p<0.05)$. Key: To = onset temperature; $T p=$ peak temperature; $T c=$ degradation temperature; $D H=$ enthalpy of gelatinization.

\section{X-ray powder starch diffraction of native and modified parkia starch}

The x-ray diffraction patterns of crystalline types of native and modified parkia starches are shown in Figure 3. Native parkia starch showed a typical A-type pattern with strong reflections at $2 \theta$ degrees about three short peaks $(5,16$ and 24$)$ and two long peaks $\left(19\right.$ and $\left.22^{\circ}\right)$. After PD, CL and HMT, the strongest peaks were observed at around 16, 19 and $22^{\circ}$, and four peaks at around 5 and $27^{\circ}$ (b), 5, 13 and $24^{\circ}$ (c and d) were generated, exhibiting the typical characteristics of B-type starch. In addition to B-type crystallinity, an additional peak at $22^{\circ}$ was clearly observed, indicating the presence of $\mathrm{V}$-type crystallinity in the modified parkia starch.
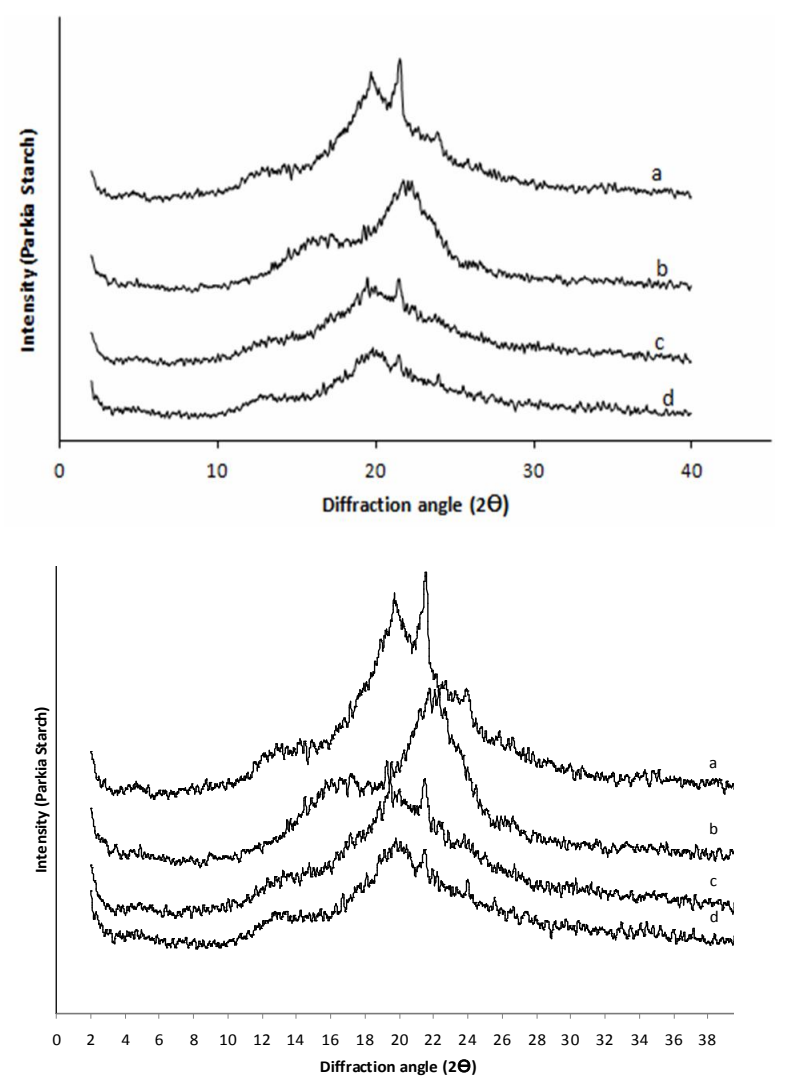

Figure 3: X-ray diffractograms of native starch (a) and those modified by pyrodextrinization (PD, b), crosslinking $(\mathrm{CL}, \mathrm{c})$ and heat-moisture $(\mathrm{HMT}, \mathrm{d})$ treatments

\section{Thermal properties of native and modified starches}

The effect of PD, CL and HMT on the gelatinization endotherms of native and modified starches are shown in Table 2. A significant increase $(p<0.05)$ was observed in the onset temperature of gelatinization (To) of PD, CL and HMT treated starches. The gelatinization enthalpies $(\Delta \mathrm{H})$ of the PD, CL and HMT-modified parkia starch decreased significantly $(p<0.05)$ compared with native starch.

\section{DISCUSSION}

The purity of the parkia starch obtained in the present study, based on its low protein, ash and lipid contents, makes it suitable for the production of syrups with high glucose content. Similar results were reported by Hoover and Ratnayake [15]. Thus, amylose content has a significant effect on functional and physicochemical properties, including pasting, gelatinization, retrogradation and swelling behaviour of starch.

Our in vitro starch digestibility results corroborate those of Zhang et al [16] in waxy maize, wheat, rice and maize starches. The RDS, SDS and RS levels of the parkia starches cannot be compared with those reported for other legume starches, due to differences in methods used and different duration of hydrolysis that were used for determination of RDS, SDS and RS levels. A moderate postprandial glycemic and insulinemic response of SDS implies that SDS rich foods may provide wide health benefits in alleviating common chronic diseases such as obesity, diabetes, and cardiovascular disease through lessening the stress on regulatory systems related to glucose homeostasis $[4,17]$.

The effect of pyrodextrinization, cross-linking and heat-moisture treatments on parkia starch that demonstrated higher RDS was expected due to its granular structure which renders it more susceptible to enzymatic hydrolysis. However, the proportion of RDS fraction of starch PD, CL 
and HMT starches implies that new structural changes occurred after $\mathrm{CL}$ and HMT rendering the starch resistant to a-amylase attack. This might be due to leaching of the amylose from the granules into solution as a random coil polymer, whereas the crystalline regions of clusters of branched amylopectin chains had disappeared $[6,7]$. However, it was distinctly increased after physical and chemical treatments, indicating low digestibility of the modified starch samples. No significant data have been reported, to the best of our knowledge, comparing the levels of RDS, SDS, and RS legume starch; most of the studies reported used different digestibility methods varying in time of hydrolysis and enzyme sources. It is well known that the contents of starch fractions (RDS, SDS and RS) are affected by various factors such as amylose content, swelling power, granule surface area and starch crystalline structure [6].

The low significant swelling power of native starch is notable and as well as that PD treatment caused slightly higher swelling of the starch than those modified by $\mathrm{CL}$ and HMT treatment. This swelling may be due to $t$ PD producing partial changes in the amorphous regions of the starch structure. Thus, the starch partially lost the ability to hold absorbed water. $\mathrm{CL}$ reinforced the structure of starch granules and limits water absorption by restricting the mobility of starch chains in the amorphous region. In the case of HMT treatment, additional interactions may have occurred between amylose-amylose and amylose-amylopectin chains which restricted swelling. Amylose amylose interaction after PD and HMT treatment might have reduced the mobility of the amorphous region, leading to increase in gelatinization temperature. As explained above, $\mathrm{CL}$ limits water absorption and therefore delayed gelatinization. A similar result for increment in solubility after HMT has been reported for finger millet starch [14], indicating that HMT starches have a higher solubility than that of native starch.

After PD and CL, we noted a significant increase in starch solubility. The solubility of parkia starch after PD, may be explained by increase in the low molecular weight linear fractions with hydroxyl groups that facilitates solubilization in hot water. There was increase in solubility as temperature increased. Solubility increased as the temperature increased because of increase in the mobility of the starch granules, which facilitated enhanced dispersion of starch molecules in water. It is suggested that HMT starch might have made it easier for water to access the amorphous regions of the starch and the remaining unassociated starch chains can solubilize in water, and therefore increase the solubility of starch.

SEM changes can be attributed to interplay of factors such as amylose content, interaction between starch chains, arrangement of amylose chains within the amorphous domains and lipidamylose complexes. The morphology of chemically and physically modified granules depends on the botanical source of starch. In this case, crystalline perfection and amyloseamylose and/or amylose-amylopectine interactions might have theoretically increased RS level.

X-ray diffraction of the modified parkia starch revealed the coexistence of B- and V-types of starch comparable to that reported for corn starch [18]. However, the increased intensity of the peak at $5^{\circ}$ which is a fingerprint of B-type starch structure suggests that the content of RS was increased by chemical cross-linking.

Since crosslinking limits water absorption and delayed gelatinization, therefore, gelatinization enthalpies $(\Delta H)$ of the PD, CL and HMT parkia starch decreased. The reduced enthalpy may be attributed to the transformation of the intercrystalline part into an amorphous phase, and thus the crystalline regions would melt more easily, i.e., with lower energy. Lim et al [19] reported that the relative decrease in double helix content parallels the relative decrease in both crystallinity and enthalpy of gelatinization $(\Delta \mathrm{H})$. This agrees with the lowest enthalpy of gelatinization value assessed in the $\mathrm{PD}, \mathrm{CL}$ and HMT parkia starch and with the lowest SDS and slight increased RS contents in the samples.

\section{CONCLUSION}

Parkia starch is suitable for incorporation into foods subjected to high temperature processing, high shear, and frozen storage due to higher thermal stability. However, this would require extensive modification of the starch before it can be utilized in the food industry. It has been demonstrated in this study that native parkia starch modified by pyrodextrinization, crosslinking and heat-moisture treatment may be useful in the development of new starch products with reduced calorie and slower glycemic response in humans since resistant starch has received much attention for both its potential health benefits and functional properties.

\section{ACKNOWLEDGEMENT}

This research was supported by 111 projectB07029 and PCSIRT062, China National 
Science Fund.. Authors are also grateful to Fatoumata Sylla, Ministry of Foreign Affairs, Conakry, Guinea, for assistance in transporting materials from Guinea to Wuxi, China.

\section{REFERENCES}

1. Ihegwuagu NE, Omojola MO, Emeje MO, Kunle, OO. Isolation and evaluation of some physicochemical properties of Parkia biglobosa starch. Pure App Chem. 2009; 81: 97-104.

2. Singh J, Kaur L, McCarthy OJ, Factors influencing the physicochemical, morphological, thermal and rheological properties of some chemically modified starches for food applications $-A$ review. Food Hydrocol. 2007; 21: 1-22.

3. Chaulang G, Patel P, Hardikar S, Kelkar M, Bhosale A Bhise S. Formulation and evaluation of solid dispersions of furosemide in sodium starch glycolate. Trop J Pharm Res. 2009; 8(1): 43-51.

4. Juansang J, Puttanlek C, Rungsardthong V, Punchaarnon S, Uttapap D. Effect of gelatinisation on slowly digestible starch and resistant starch of heat-moisture treated and chemically modified canna starches. Food Chem. 2012; 131(2): 500507.

5. Khondkar D, Tester RF, Karkalas J. Effect of crosslinking on the resistance to enzymatic hydrolysis of waxy maize starch and low-methoxy pectin. Food Hydrocol. 2009; 23: 387-393.

6. Yoshimi S, Toshiko W. Some properties of lentil starches. J Home Eco Japan 2006; 56: 635-640.

7. Sankhon A, Yao WR, Wang $H$, Qian $H$, Sangare M. The yield improvement of resistant starches from Africa locust (Parkia biglobosa): The influence of heatmoisture, autoclaving-cooling and cross-linking treatments. Am J Food Technol. 2012; 7: 386-397.

8. Wang JY, Kozlowski $R$, Delgado GA. Enzyme resistant dextrins from high amylose corn mutant starches. Starch 2001; 53: 21-26.

9. Perez-Sira EE, Amaiz ML. A laboratory scale method for isolation of starch from pigmented sorghum. J Food Eng. 2004; 64: 525-519.
10. AACC International. Approved methods of the American Association of Cereal Chemists (10 ${ }^{\text {th }}$ Ed.). 2000; St. Paul, MN, USA

11. Rose $R$, Rose CL, Omi SK, Forry KR, Durall DM, Bigg WL. Starch determination by perchloric acid vS enzymes: evaluating the accuracy and precision of six colorimetric methods. J Agrc Food Chem.1991; 39: 2-11.

12. Campechano-Carrera E. Corona-Cruz A. Chel-Guerrero $L$. Betancur-Ancona $D$. Effect of pyrodextrinization on available starch content of Lima bean (Phaseolus lunatus) and Cowpea (Vigna unguiculata) starches. Food Hydrocol. 2007; 21: 472-479.

13. Koo SH, Lee KY, Lee HG. Effect of cross-linking on the physicochemical and physiological properties of corn starch. Food Hydrocol. 2010; 24: 619-625.

14. Adebowale KO, Afolabi TA, Olu-Owolabi BI. Hydrothermal treatments of Finger millet (Eleusine coracana) starch. Food Hydr. 2005; 19(6): 974983.

15. Hoover R, Ratnayake WS. Starch characteristics of black bean, chickpea, lentil, navy bean and pinto bean cultivarswn in Canada. Food Chem. 2002; 78: 489-498.

16. Zhang G, Zihua AO, Hamaker B. Nutritional property of endosperm starches from maize mutants: $A$ parabolic relationship between slowly digestible starch and amylopectin fine structure. J Agric Food Chem. 2008; 56(12): 4686-4694.

17. Khan SA, Ahmad M, Murtaza G, Aamir MN, Rehman N, Kousar R, Rasool F, Akhtar M. Formulation of nimesulide floating microparticles using lowviscosity hydroxypropyl methylcellulose. Trop J Pharm Res. 2010; 9(3): 293-299.

18. Chamg HJ, Jeong HY, Lim ST. Effects of acid hydrolysis and defatting on pasting crystallinity and properties of freeze-thawed high amylase corn starch. Carbohydr polym. 2003; 54: 449-455.

19. Lim ST, Han JA, Lim HS, BeMiller JN. Modification of starch by dry heating with ionic gums. Cereal Chem. 2002; 79(5): 601-606. 